\title{
Can community health worker home visiting improve care-seeking and maternal and newborn care practices in fragile states such as Afghanistan? A population-based intervention study
}

Karen M. Edmond ${ }^{1 *}$, Khaksar Yousufi ${ }^{1}$, Zelaikha Anwari ${ }^{2}$, Sayed Masoud Sadat ${ }^{3}$, Shah Mansoor Staniczai ${ }^{4}$, Ariel Higgins-Steele', Alexandra L. Bellows ${ }^{5}$ and Emily R. Smith

\begin{abstract}
Background: The effects of community health worker (CHW) home visiting during the antenatal and postnatal periods in fragile- and conflicted-affected countries such as Afghanistan are not known.

Methods: We conducted a non-randomised population-based intervention study from March 2015 to February 2016. Two intervention and two control districts were selected.

All female CHWs in the intervention districts were trained to provide eight home visits and behaviour change communication messages from pregnancy to 28 days postpartum. The primary outcome was the proportion of women who reported delivering in a health facility. Secondary outcomes were the proportion of women who reported attending a health facility for at least one antenatal and one postnatal visit. Outcomes were analysed at 12 months using multivariable difference-in-difference linear regression models adjusted for clustering.

Results: Overall, 289 female CHWs in the intervention districts performed home visits and 1407 eligible women (less than 12 months postpartum) at baseline and 1320 endline women provided outcome data (94\% response rate). Facility delivery increased in intervention villages by $8.2 \%$ and decreased in the control villages by $6.3 \%$ (adjusted mean difference (AMD) 11.0\%, 95\% confidence interval (CI) 4.0-18.0\%, $p=0.002$ ). Attendance for at least one antenatal care visit (AMD 10.5\%, 95\% Cl 4.2-16.9\%, $p=0.001$ ) and postnatal care visit (AMD 7.2\%, 95\% Cl 0.2-14.2\%, $p=0.040$ ) increased in the intervention compared to the control districts.
\end{abstract}

Conclusions: CHW home visiting during the antenatal and postnatal periods can improve health service use in fragileand conflict-affected countries. Commitment to scale-up from Ministries and donors is now needed.

Trial registration: This trial was retrospectively registered at the Australian and New Zealand Clinical Trial Registry (ACTRN12618000609257).

Keywords: Community, maternal, newborn

\footnotetext{
* Correspondence: kedmond@unicef.org

1 UNICEF Afghanistan, UNOCA, Jalalabad Road, Kabul, Afghanistan

Full list of author information is available at the end of the article
}

(c) The Author(s). 2018 Open Access This article is distributed under the terms of the Creative Commons Attribution 4.0 International License (http://creativecommons.org/licenses/by/4.0/), which permits unrestricted use, distribution, and reproduction in any medium, provided you give appropriate credit to the original author(s) and the source, provide a link to the Creative Commons license, and indicate if changes were made. The Creative Commons Public Domain Dedication waiver (http://creativecommons.org/publicdomain/zero/1.0/) applies to the data made available in this article, unless otherwise stated. 


\section{Background}

There have been substantial improvements in the provision of maternal and newborn health $(\mathrm{MCH})$ services in Afghanistan in recent years [1]. However, key indicators, such as receipt of any antenatal care (ANC) (59\%) or postnatal care (PNC) for newborns (9\%), remain low [2]. Afghanistan continues to have a fragile and challenging environment for women wishing to obtain healthcare, with maternal and newborn mortality rates remaining among the highest globally [2-4]. Reasons for this include persistent levels of violence and conflict, which limit the ability of many mothers and families to leave the home to receive health and social care [5-7]. Other important barriers are poverty, the mountainous terrain and lack of decision-making 'power' of women within the family [2].

Studies over the last 5 years in poor communities in south Asia and Africa have conclusively shown that community health worker ( $\mathrm{CHW}$ ) home visiting during the antenatal and postnatal periods can improve both the demand for and use of ANC, delivery and PNC services, and reduce maternal and newborn mortality by at least 15-20\% [8-11]. CHWs are increasingly being 'institutionalised' in the workforce in south Asia and Africa through enhanced training and incentive packages [12-14].

Home visiting from female CHWs during the antenatal and postnatal periods is likely to be an important way to improve the demand for and use of $\mathrm{MCH}$ services in fragile and conflict-affected countries such as Afghanistan [7, 12, 15, 16]. Many CHW studies have been conducted in Africa and South Asia [8, 10]. However, to our knowledge, there have been no published studies of the effectiveness of home visiting by CHWs in conflict-affected districts or provinces.

Volunteer CHWs have been part of the health system in Afghanistan since 2001, but have not been routinely used for home visiting during the antenatal and postnatal periods [17]. In 2015, the Ministry of Public Health in Afghanistan, together with UNICEF and Save the Children, implemented a study to understand if home visiting by $\mathrm{CHW}$ for $\mathrm{MCH}$ could be effective in conflict-affected districts. The overall aim was to assess whether a CHW home visiting programme could improve care-seeking and newborn care practices in mothers living in the challenging environment of rural Afghanistan.

The primary objective was to assess the effects of the Afghanistan CHW home visiting programme on the proportion of women delivering in a health facility. Secondary outcomes were to assess the effects on the proportion of women who attended a health facility for at least one ANC and one PNC visit. In addition, we assessed effects on birth preparedness and newborn care practices, especially early initiation of exclusive breastfeeding. Effects on the knowledge of mothers about their own and their infant's health were also assessed.

\section{Methods}

\section{Study setting}

This study was based in Bamyan and Kandahar provinces of Afghanistan. Bamyan is located in the central, mountainous, highland region of Afghanistan and Kandahar is in the southern, sub-desert region bordering eastern Pakistan.

The primary healthcare system includes accredited nurses and doctors who work in sub-centres, basic health centres, comprehensive health centres, and national, regional, provincial and district hospitals $[17,18]$. The doctors and midwives provide all medical tests, medical examinations, and ANC, PNC and birthing services in the health facilities. The primary healthcare system also includes volunteer CHWs who work in 'health posts' (usually their own home in their own villages) [17]. New CHWs receive 3 months of initial training followed by annual refresher training. CHWs perform annual censuses through house-to-house visiting, which are recorded on pictorial tally sheets. Women of reproductive age are visited quarterly, new pregnancies are recorded and household listings are updated. CHWs are also trained to act as 'civil registration vital statistics' key informants in the villages. Village members are asked to report all pregnancies, births and deaths to the CHWs. The CHWs report the civil registration vital statistics data to their supervisors monthly. CHWs are also trained to provide family planning, maternal and child health promotion education, basic medicines (e.g. oral contraceptives, iron and folic acid, antibiotics, oral rehydration solution), and to refer mothers and children with significant illness and danger signs. CHWs are not accredited to provide medical or birthing services, these must be provided by accredited doctors and midwives. The CHWs are supervised by paid community health supervisors who provide monthly village-based supportive supervision.

\section{Design}

This was a non-randomised, population-based intervention study conducted over a 12-month period from September 2015 to August 2016 in Bamyan and Kandahar provinces. For the evaluation, the baseline survey was conducted over a 1-month period in August 2015 and the endline survey was conducted in July 2016.

We used World Bank and Central Statistics Organization definitions to categorise all districts in Bamyan and Kandahar provinces into 'conflict-affected', 'remote,' 'mountainous' and 'poor quintile' categories and to quantify their health services [2,19-21]. The project team purposively selected two intervention districts per province (Arghandab, Dand, Bamyan, Yakawalang) to ensure 'conflict-affected' areas, 'remote' and 'mountainous' regions were represented. Two control districts per province (Speenboldak, Daman, Panjab and Waras) were then purposively chosen with similar sociodemographics, access 
and conflict status. Figure 1 displays the map of the study area. Tables 1 and 2 display district profile data and definitions. Intervention and control districts were similar in terms of population size, conflict risk, remoteness, mountainous terrain, wealth quintile and number of health centres. All districts had poor road infrastructure (over 50\% of roads unsealed).

\section{Intervention}

The intervention was a standardised training and supportive supervision package aimed at improving existing CHW capacity to provide maternal and neonatal home visits and behaviour change communication (BCC) messages from as early as possible in the antenatal period to 28 days postpartum. It was specifically targeted to female CHWs in the study area. All (100\%) 289 female CHWs in the study area received the training package.

The intervention had five components. (1) Structured home visiting schedule. Each $\mathrm{CHW}$ was trained to provide eight home visits (four during the antenatal period and four in the postnatal period (days 1, 3, 7 and 28) and to provide health promotion and $\mathrm{BCC}$ messages at each visit. (2) Structured and simplified MCH BCC training 'curriculum'. This was based on the standardised World Health Organization/UNICEF CHW training package [22]. It included key messages that the $\mathrm{CHW}$ should provide to mothers about birth preparedness, care-seeking for ANC, delivery care and newborn care. As most of the CHWs in Afghanistan cannot read or write, locally appropriate tools were developed and pre-tested, including pictorial counselling flip cards for birth preparedness, ANC, facility delivery, newborn greetings, PNC of mother and newborn, and maternal and newborn danger signs. Each training session lasted for 5 days and was followed by three 4-hour 'on the job' refresher sessions over a 12-month intervention period. (3) Structured 'Training of Trainers' programme. Two female government reproductive health provincial officers, one per district, were trained over a 5-day period using locally developed tools and training curriculum. The supervisors then provided training to the female CHWs as described above. (4) Supportive supervision programme. The female $\mathrm{CHWs}$ were visited once per month by their supervisors, who provided advice and monitoring, over a period of 12 months. These visits included both scheduled and random unscheduled visits. (5) Performance-based incentive programme. CHWs were provided with a family kit (consisting of cooking and eating utensils including pots, plates, spoons, towels and soap) (total cost approximately \$21 USD per kit) for their own use at the beginning of the project if they mapped and registered pregnant women in their catchment areas. They were provided with an additional kit if the woman delivered at a health facility. Programmatic data about the number of CHWs and the intensity of their work and monitoring in the intervention districts are provided in Table 3. These data were collected by the study supervisors during their monthly supervision visits.

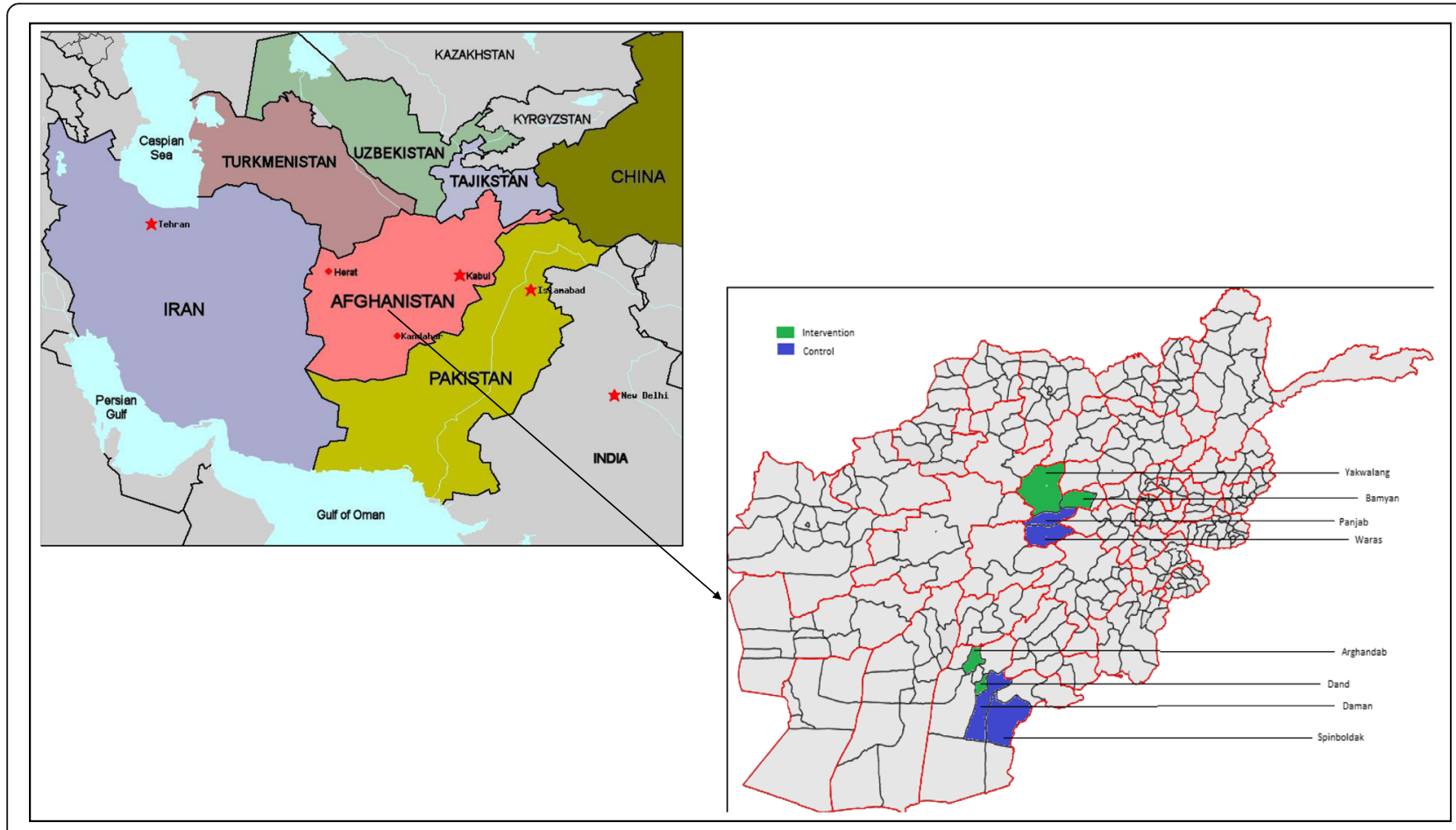

Fig. 1 Map of Afghanistan and intervention and control districts 
Table 1 Sociodemographic characteristics of women included in the study compared between intervention and control villages

\begin{tabular}{|c|c|c|c|c|}
\hline & \multicolumn{2}{|c|}{ Number (\%) of mothers in intervention villages } & \multicolumn{2}{|c|}{ Number (\%) of mothers in control villages } \\
\hline & Baseline & Endline & Baseline & Endline \\
\hline & $(n=709)$ & $(n=689)$ & $(n=699)$ & $(n=689)$ \\
\hline Mother's age (mean, SD) & $27.9(6.4)$ & $27.8(6.6)$ & $28.8(6.3)$ & $28.4(6.7)$ \\
\hline \multicolumn{5}{|l|}{ Mother's education level } \\
\hline None & $459(64.7 \%)$ & $460(66.9 \%)$ & $408(58.4 \%)$ & $448(66.2 \%)$ \\
\hline Primary (grade 6) & $94(13.3 \%)$ & $48(7.0 \%)$ & $213(30.5 \%)$ & $53(7.8 \%)$ \\
\hline Secondary (grade 9) & $27(3.8 \%)$ & $27(3.9 \%)$ & $21(3.0 \%)$ & $34(5.0 \%)$ \\
\hline High school (grade 12) & $23(3.2 \%)$ & $21(3.1 \%)$ & $24(3.4 \%)$ & $28(4.1 \%)$ \\
\hline University & $20(2.8 \%)$ & $10(1.5 \%)$ & $11(1.6 \%)$ & $10(1.5 \%)$ \\
\hline Madrassa & $86(12.1 \%)$ & $116(16.9 \%)$ & $22(3.2 \%)$ & $92(13.6 \%)$ \\
\hline \multicolumn{5}{|l|}{ Ethnic language group } \\
\hline Dari & $356(50.2 \%)$ & $331(49.8 \%)$ & $353(50.6 \%)$ & $358(52.1 \%)$ \\
\hline Pashtun & $353(49.8 \%)$ & $334(50.2 \%)$ & $345(49.4 \%)$ & $329(47.9 \%)$ \\
\hline \multicolumn{5}{|l|}{ Husband/partner's education } \\
\hline None & $335(47.3 \%)$ & $278(40.7 \%)$ & $286(41.1 \%)$ & $360(53.4 \%)$ \\
\hline Primary (grade 6) & $96(13.5 \%)$ & $80(11.7 \%)$ & $214(30.6 \%)$ & $51(7.6 \%)$ \\
\hline Secondary (grade 9) & $62(8.7 \%)$ & $60(8.8 \%)$ & $57(8.2 \%)$ & $31(4.6 \%)$ \\
\hline High school (grade 12) & $52(7.3 \%)$ & $56(8.2 \%)$ & $37(5.3 \%)$ & $37(5.5 \%)$ \\
\hline University & $45(6.4 \%)$ & $48(7.0 \%)$ & $32(4.6 \%)$ & $37(5.5 \%)$ \\
\hline Madrassa & $119(16.8 \%)$ & $165(24.2 \%)$ & $72(10.3 \%)$ & $156(23.2 \%)$ \\
\hline \multicolumn{5}{|l|}{ Husband/partner's occupation } \\
\hline Does not work & $29(4.2 \%)$ & $25(3.7 \%)$ & $34(5.0 \%)$ & $19(2.8 \%)$ \\
\hline Servant/household worker & $6(0.9 \%)$ & $5(0.7 \%)$ & $17(2.5 \%)$ & $10(1.5 \%)$ \\
\hline Farmer & $259(37.4 \%)$ & $266(39.2 \%)$ & $229(33.8 \%)$ & 199 (20.8\%) \\
\hline Livestock herder & $15(2.2 \%)$ & $10(1.5 \%)$ & $17(2.5 \%)$ & $18(2.7 \%)$ \\
\hline Labourer & $116(16.7 \%)$ & $142(20.9 \%)$ & $144(21.2 \%)$ & $202(30.2 \%)$ \\
\hline Street seller/vendor & $12(1.7 \%)$ & $22(3.1 \%)$ & $14(2.1 \%)$ & $19(2.8 \%)$ \\
\hline Shopkeeper & $156(22.5 \%)$ & $103(15.2 \%)$ & $137(20.2 \%)$ & $126(18.9 \%)$ \\
\hline Businessman & 18 (2.6\%) & 10 (1.5\%) & $8(1.2 \%)$ & $11(1.7 \%)$ \\
\hline
\end{tabular}

\section{Control areas}

The control districts received standard care by CHWs who did not receive specific training in home visiting, $\mathrm{MCH}$ and BCC. All health facilities in the intervention and control areas received a health system strengthening package over the 12 months prior to the intervention delivery and throughout the intervention period. This included (1) the standard World Health Organization/ UNICEF training package to midwives and neonatal nurses in essential newborn care (ENC) and Emergency Obstetric and Newborn Care and (2) training to local community health action groups on the importance of essential antenatal and newborn care.

\section{Data collection}

Baseline and endline data were collected from women who were less than 12 months postpartum using a standardised structured survey questionnaire based on the Centers for Disease Control KPC 2000 tool [23]. Survey domains included self-reported baseline socioeconomic status, service use for ANC, delivery and PNC, birth preparedness (including seeking care for maternal postnatal complications, saving money for transportation for emergency obstetric care, pre-planning for a skilled birth attendant (SBA), arranging for a blood donor and newborn care practices (initiating breastfeeding within 1 hour of birth)), and knowledge about ANC, delivery, PNC and birth preparedness.

A separate independent team of female data collectors were trained over a 5-day period and were supervised by two independent data supervisors. The data supervisors performed spot (unscheduled) checks of approximately $10 \%$ of the surveys together with a member of the study team. An additional $10 \%$ of surveys were selected for re-survey. The data supervisors reviewed each survey 
Table 2 Sociodemographic characteristics of the intervention and control districts

\begin{tabular}{|c|c|c|c|c|c|c|c|c|}
\hline Intervention or control area & Intervention & Intervention & Intervention & Intervention & Control & Control & Control & Control \\
\hline \multicolumn{9}{|l|}{ Design } \\
\hline Province & Bamyan & Bamyan & Kandahar & Kandahar & Bamyan & Bamyan & Kandahar & Kandahar \\
\hline District & Bamyan & Yakawlang & Arghandaab & Dand & Panjab & Waras & Damaan & Speen Boldak \\
\hline \multicolumn{9}{|l|}{ District population data } \\
\hline Total population & 55,123 & 57,559 & 69,094 & 83,392 & 53,501 & 84,826 & 15,815 & 88,622 \\
\hline Women of child-bearing age & 11,198 & 11,870 & 14,356 & 15,678 & 11,456 & 16,743 & 3678 & 18,765 \\
\hline Distance in km from provincial capital & 110 & 130 & 110 & 155 & 140 & 160 & 100 & 120 \\
\hline \multicolumn{9}{|l|}{ Health system characteristics } \\
\hline Sub-centres & 4 & 3 & 4 & 5 & 4 & 5 & 2 & 4 \\
\hline Basic health centres & 3 & 3 & 3 & 3 & 3 & 4 & 2 & 3 \\
\hline Comprehensive health centres & 3 & 2 & 3 & 4 & 3 & 4 & 2 & 3 \\
\hline District hospitals & 1 & 1 & 1 & 1 & 1 & 1 & 1 & 1 \\
\hline Mobile health teams & 1 & 2 & 0 & 0 & 2 & 3 & 0 & 1 \\
\hline \multicolumn{9}{|l|}{ Demographic characteristics } \\
\hline Conflict risk $^{\mathrm{a}}$ & Low & Medium & High & High & Low & Medium & High & High \\
\hline Remote $^{b}$ & Yes & Yes & Yes & Yes & Yes & Yes & Yes & Yes \\
\hline Mountainous $^{c}$ & Yes & Yes & No & No & Yes & Yes & No & No \\
\hline Lowest wealth quintile $^{d}$ & $81 \%$ & $39 \%$ & $74 \%$ & $32 \%$ & $65 \%$ & $35 \%$ & $71 \%$ & $40 \%$ \\
\hline
\end{tabular}

${ }^{a}$ Conflict affected = use of armed force between warring parties in a conflict dyad, be it state based or non-state, resulting in deaths); 25 deaths or less in the previous 12 months is categorised as low intensity, 25-100 is categorised as moderate intensity and 100+ is categorised as high intensity [20, 21]

${ }^{\mathrm{b}}$ Remote $=$ District centre more than $2 \mathrm{~h}$ away by any form of transport from provincial capital [20, 21]

${ }^{c}$ Mountainous $=$ more than $1800 \mathrm{~km}$ elevation at highest point of district $[20,21,41]$

${ }^{d}$ Lowest wealth quintile $=$ As per the Afghanistan Living Standards Survey 2015 using Principal Components Analysis [41]

form and they were not submitted for data entry until they were considered complete and without error. An additional random subsample of $10 \%$ of survey forms were also reviewed in the first month of data collection.

\section{Data analysis}

For the outcome evaluation, we assessed mean differences in key variables from baseline (data collection immediately prior to the intervention) to endline (data collection 12 months after the intervention commenced) and compared the effects in the intervention areas compared to control areas. We randomly selected households to be visited in each district using a standard two-stage sampling method with probability of selection proportional to size (i.e. random selection of villages followed by random selection of households) [24-26]. The sampling frame was obtained from the Central Statistics Organization, which listed the names of the districts, their villages and their population size. Use of the same cooking hearth was used to define a household.

The primary outcome measure was the proportion of women who reported delivering in a health facility in the study area. Secondary outcome measures were the proportion of women who received at least one ANC visit, proportion of women who received at least one PNC visit, and the proportion of women who initiated breastfeeding within $1 \mathrm{~h}$ postpartum. Information on improvements in mothers' knowledge about their own and their infant's health was also analysed.

We calculated that we required a sample size of 1400 women to provide $80 \%$ power at a $5 \%$ significance level for the primary outcome. These calculations were based on recent data at the provincial level, which indicated that there would be a baseline level of facility delivery of $61 \%$ [2], and previous studies that indicated that there would be at least a $20 \%$ change in service use due to the intervention [8]. We also assumed that there would be one eligible woman per household. We calculated that this sample size would also provide adequate power for the secondary outcomes.

We used a multivariable 'difference-in-differences' approach to estimate the mean effect of the intervention on each outcome [27]. The difference-in-differences approach is based on comparing mean differences in the intervention group (before and after the intervention) to mean differences in the control group and assumes that trends in both groups are the same in the absence of the intervention [24]. Multivariable linear regression models were constructed to adjust for clustering by district and potential confounders decided a priori and to calculate adjusted mean differences (AMD), 95\% confidence intervals $(95 \% \mathrm{CI})$ and corresponding $p$ values. 
Table 3 Community health worker home visiting in intervention districts

\begin{tabular}{|c|c|c|c|}
\hline & Bamyan & Kandahar & Total $^{a}$ \\
\hline Population & 112,682 & 152,486 & 265,168 \\
\hline Number of villages & 150 & 131 & 281 \\
\hline Number of female CHWs & 154 & 135 & 289 \\
\hline Population size per CHW & 732 & 1130 & 918 \\
\hline Number of pregnant women in study area & 2050 & 3730 & 5780 \\
\hline Number of pregnant women per $\mathrm{CHW}$ & 13 & 28 & 20 \\
\hline \multicolumn{4}{|l|}{ Number (\%) of women who received: } \\
\hline First CHW antenatal visit & $1242(60.6 \%)$ & $3436(92.1 \%)$ & $4125(71.4 \%)$ \\
\hline Second CHW antenatal visit & $575(28.0 \%)$ & $393(10.5 \%)$ & $968(16.7 \%)$ \\
\hline Third CHW antenatal visit & $598(29.2 \%)$ & $382(10.2 \%)$ & $980(17.0 \%)$ \\
\hline Fourth CHW antenatal visit & $458(22.3 \%)$ & $272(7.3 \%)$ & $730(12.6 \%)$ \\
\hline First CHW postnatal visit day $1-2^{b}$ & $1421(69.3 \%)$ & $3029(81.2 \%)$ & $4129(71.7 \%)$ \\
\hline Second CHW postnatal visit day 3 & $368(18.0 \%)$ & $113(3.0 \%)$ & $481(8.3 \%)$ \\
\hline Third CHW postnatal visit day 7 & $330(16.1 \%)$ & $113(3.0 \%)$ & $443(7.7 \%)$ \\
\hline Fourth CHW postnatal visit day 28 & $198(9.7 \%)$ & $82(2.2 \%)$ & $280(4.8 \%)$ \\
\hline Total number of $\mathrm{CHW}$ visits in 12-month period & 5180 & 7706 & 12,886 \\
\hline Number of visits per CHW in 12-month period & 33.6 & 57.1 & 44.6 \\
\hline Number of visits per CHW per month & 2.8 & 4.8 & 3.7 \\
\hline Number of visits per woman & 2.5 & 2.1 & 2.2 \\
\hline \multicolumn{4}{|l|}{ Monitoring } \\
\hline Number (\%) of CHWs who received at least one supportive supervision visit & $154(100 \%)$ & 135 (100\%) & $289(100 \%)$ \\
\hline Number (\%) of CHWs who received two or more supportive supervision visits & $150(97.4 \%)$ & $129(95.6 \%)$ & 279 (96.5\%) \\
\hline
\end{tabular}

CHW community health worker

${ }^{a}$ Kandahar intervention districts: Arghandab, Dand; Bamyan intervention districts: Bamyan, Yakawalang

${ }^{\mathrm{b}}$ This is a visit within the first $48 \mathrm{~h}$ after birth. We had exact timing data for 4393 of the 5780 mothers (76\%); 966 (22\%) were visited at $0-23 \mathrm{~h}$ and 3427 (88\%) were visited at $24-47 \mathrm{~h}$ post birth

In the endline sample, we also assessed whether attending ANC, knowledge about birth preparedness, or sociodemographic factors were associated with facility or SBA-attended birth. Log Binomial and Poisson models with robust variances were used to estimate adjusted relative risks (adjRR), 95\% CIs and corresponding $p$ values [28]. SAS version 9.4 was used for all analyses.

\section{Results}

All 289 female CHWs in the intervention districts were trained (135 in Kandahar Province (Arghandab and Dand districts) and 154 in Bamyan Province (Yakawalang and Bamyan) districts) (Table 3); 94\% (2780 out of 2947 ) of the women in the study area agreed to participate (1408 women at baseline and 1372 women at endline). The CHWs performed 12,886 home visits to pregnant or postpartum women over the 12-month intervention period (3.7 visits per CHW per month) (Table 3). In total, 5780 pregnant or postpartum women were estimated to receive the intervention. Each CHW visited approximately 20 women and each woman received an average of 2.2 home visits throughout the antenatal and postpartum periods (mean 2.5 Bamyan, mean 2.1 Kandahar) (Table 3). Overall, 4125 (71.4\%) women received a first ANC visit and 4127 (71.5\%) received a visit within $48 \mathrm{~h}$ of birth, but only $730(12.6 \%)$ received a fourth ANC visit and 280 (4.8\%) received a fourth PNC visit on approximately day 28 postpartum.

Evaluation survey data were collected from 2780 women. Demographic characteristics were similar between intervention and control districts (Table 1). Overall, $66 \%$ of women had no education and $80 \%$ of their partners worked as farmers or labourers or were unemployed (Tables 1 and 2). Only maternal primary school education was statistically significantly different between the intervention and control groups $(p=0.02)$.

\section{Service use}

Facility delivery increased in intervention villages by $8.2 \%$ and decreased in the control villages by $6.3 \%$ (AMD 11.0\%, 95\% CI 4.0-18.0\%, $p=0.002$ ). There were similar significant increases in the proportion of women whose delivery was attended by a SBA in the 
intervention areas as compared to the control areas (AMD 14.2\%, 95\% CI 7.3-21.2\%, $p<0.0001$ ) (Table 4). Attendance for at least one ANC visit improved 3.4\% in intervention villages (from $71.5 \%$ to $74.9 \%$ ), while ANC attendance declined in control villages (from $80.8 \%$ to 70.9\%) (AMD 10.5\%, 95\% CI 4.2\%-16.9\%, $p=0.040$ ). Attendance for at least one PNC visit (AMD 7.2\%, 95\% CI $0.2-14.2 \%, p=0.040$ ) increased in the intervention compared to the control districts (Table 4). The proportion of women who sought care for maternal postnatal complications increased by $14.0 \%$ in the intervention compared to the control villages (AMD 14.0\%, 95\% CI $4.1-23.9 \%, p=0.006)$. The proportion of women who sought care for maternal antenatal complications also increased in the intervention compared to the control villages (AMD 2.8\%, 95\% CI -6.2 to $-11.8 \%, p=0.540$ ), though this change was not statistically significant (Table 4).

\section{Birth preparedness}

The intervention appeared to have little effect on birth preparedness. The proportion of women who reported that they saved money for transportation for emergency obstetric care, pre-planned for a SBA and arranged for a blood donor was similar between intervention and control districts (Table 5).

Table 4 Service use and care seeking in women included in the study compared between intervention and control villages

\begin{tabular}{|c|c|c|c|c|c|c|}
\hline & $\begin{array}{l}\text { Number (\%) of mothers } \\
\text { in intervention villages }\end{array}$ & $\begin{array}{l}\text { Number (\%) of mothers } \\
\text { in control villages }\end{array}$ & $\begin{array}{l}\text { Crude mean } \\
\text { difference }(95 \% \mathrm{Cl})\end{array}$ & $p$ value & $\begin{array}{l}\text { Adjusted mean } \\
\text { difference }^{\mathrm{a}}(95 \% \mathrm{Cl})\end{array}$ & $p$ value \\
\hline \multicolumn{7}{|l|}{ Antenatal care } \\
\hline \multicolumn{7}{|c|}{ Attended at least one antenatal care visit with a skilled healthcare provider in the previous 6 months } \\
\hline Baseline $(n=1400)$ & $507(71.5 \%)$ & $558(80.8 \%)$ & & & & \\
\hline Endline $(n=1366)$ & $513(74.9 \%)$ & $483(70.9 \%)$ & & & & \\
\hline Difference & $3.38 \%$ & $-9.82 \%$ & $13.21 \%(6.7$ to 19.7$)$ & $<0.0001$ & $10.54 \%(4.2$ to 16.9$)$ & 0.001 \\
\hline \multicolumn{7}{|c|}{ Care seeking for antenatal or delivery complications } \\
\hline Baseline $(n=866)$ & $329(75.8 \%)$ & $352(81.5 \%)$ & & & & \\
\hline Endline $(n=576)$ & $229(77.9 \%)$ & $215(76.2 \%)$ & & & & \\
\hline Difference & $2.10 \%$ & $-5.30 \%$ & $7.33 \%(-1.4$ to 16.0$)$ & 0.10 & $2.81 \%(-6.2$ to 11.8$)$ & 0.54 \\
\hline \multicolumn{7}{|l|}{ Delivery care } \\
\hline \multicolumn{7}{|l|}{ Facility delivery } \\
\hline Baseline $(n=1407)$ & $448(63.2 \%)$ & $488(69.9 \%)$ & & & & \\
\hline Endline $(n=1300)$ & $446(71.4 \%)$ & $429(63.6 \%)$ & & & & \\
\hline Difference & $8.20 \%$ & $-6.30 \%$ & $14.53 \%$ (7.5 to 21.6$)$ & $<0.0001$ & $10.97 \%$ (4.0 to 18.0$)$ & 0.002 \\
\hline \multicolumn{7}{|c|}{ Delivery attended by a skilled birth attendant } \\
\hline Baseline $(n=1407)$ & $454(64.0 \%)$ & $499(71.5 \%)$ & & & & \\
\hline Endline $(n=1320)$ & $479(74.2 \%)$ & $428(63.5 \%)$ & & & & \\
\hline Difference & $9.8 \%$ & $-8.0 \%$ & $18.1 \%(11.1$ to 25.1$)$ & $<0.0001$ & $14.22 \%(7.3$ to 21.2$)$ & $<0.0001$ \\
\hline \multicolumn{7}{|c|}{ Sought care for complications during delivery or postpartum } \\
\hline Baseline $(n=655)$ & $268(82.5 \%)$ & $292(85.9 \%)$ & & & & \\
\hline Endline $(n=377)$ & $170(87.6 \%)$ & $164(89.6 \%)$ & & & & \\
\hline Difference & $5.10 \%$ & $3.70 \%$ & $1.43 \%(-7.3$ to 10.2$)$ & 0.75 & $2.36 \%(-6.8$ to 11.5$)$ & 0.61 \\
\hline \multicolumn{7}{|l|}{ Postnatal care } \\
\hline \multicolumn{7}{|c|}{ Attended at least one postnatal care visit with a skilled healthcare provider in the previous 6 months } \\
\hline Baseline $(n=1392)$ & $337(47.9 \%)$ & $369(53.6 \%)$ & & & & \\
\hline Endline $(n=1309)$ & $319(49.6 \%)$ & $300(45.1 \%)$ & & & & \\
\hline Difference & $1.7 \%$ & $-8.5 \%$ & $10.33 \%(2.8$ to 17.9$)$ & 0.0072 & $7.20 \%(0.2$ to 14.2$)$ & 0.04 \\
\hline \multicolumn{7}{|c|}{ Sought care for maternal postnatal complications } \\
\hline Baseline $(n=739)$ & $210(61.4 \%)$ & $302(76.1 \%)$ & & & & \\
\hline Endline $(n=486)$ & $165(73.3 \%)$ & $189(72.4 \%)$ & & & & \\
\hline Difference & $11.90 \%$ & $-3.70 \%$ & $15.59 \%(5.2$ to 26.0$)$ & 0.0032 & $14.0 \%$ (4.05 to 23.9$)$ & 0.006 \\
\hline
\end{tabular}

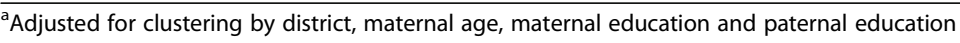




\section{Newborn care practices}

The proportion of women who initiated breastfeeding within $1 \mathrm{~h}$ of birth decreased in the intervention villages from $77.9 \%$ to 67.4\%; however, the proportion increased in the control villages (from $55.8 \%$ to $73.7 \%$ ) (AMD $-28.22 \%$, 95\% CI -35.7 to $-20.8 \%, p<0.0001$ ) (Table 5). Immediate breastfeeding rates appeared higher in home $(260,76.9 \%)$ than facility deliveries $(472,67.5 \%)$. Over $94 \%$ of women reported that they were providing breast milk to their babies in the intervention and control villages at a mean of 4 months (SD 2.5 months) postnatal in both baseline and endline samples (Table 5).

\section{Knowledge}

In general, knowledge related to birth preparedness increased in the intervention compared to the control villages (Table 6). In particular, the proportion of women who could list at least one reason for arranging for travel around the time of birth increased by almost 9\% (AMD 8.7\%, 95\% CI 2.9-14.0\%, $p=0.003$ ) (Table 6).

\section{Predictors of service use}

Maternal and paternal educational level did not appear to influence delivery at a facility or use of a SBA (Table 7).
However, young mothers $(<20$ years) were almost $20 \%$ more likely to give birth in a facility or with a SBA as compared to women aged 25-30 years (adjRR 1.19, 95\% CI $1.05-1.34, p=0.007$ ) (Table 7). Women who attended at least one ANC visit with a skilled care provider during their pregnancy were $41 \%$ more likely to deliver at a facility or with a SBA (adjRR 1.41, 95\% CI 1.27-1.58, $p<0.001$ ) than women who did not (Table 7). Birth preparedness was also associated with facility or SBA-attended delivery. In particular, women who could list at least one reason why saving money was important before childbirth were $32 \%$ more likely to deliver in a facility or use a SBA (adjRR 1.32, 95\% CI 1.18-1.47, $p<0.001)$ than women who could not list these reasons.

\section{Discussion}

Training of CHWs in home visiting and BCC skills during the antenatal and postnatal periods was associated with significantly improved care-seeking and service utilisation for facility delivery and ANC in the rural districts of Afghanistan included in our study. Facility delivery increased by $11 \%$, delivery by a SBA increased by $14 \%$, ANC attendance increased by $10 \%$ and care-seeking for

Table 5 Birth preparedness and newborn care practices in women included in the study compared between intervention and control villages

\begin{tabular}{|c|c|c|c|c|}
\hline $\begin{array}{l}\text { Number (\%) of mothers } \\
\text { in intervention villages }\end{array}$ & $\begin{array}{l}\text { Number (\%) of mothers } \\
\text { in control villages }\end{array}$ & $\begin{array}{l}\text { Crude mean } \\
\text { difference }(95 \% \mathrm{Cl})\end{array}$ & $p$ value & $\begin{array}{l}\text { Adjusted mean } \\
\text { difference }^{a}(95 \% \text { Cl) }\end{array}$ \\
\hline
\end{tabular}

Birth preparedness

Saved money for transportation for emergency obstetric care

$\begin{array}{lll}\text { Baseline }(n=1377) & 475(67.6 \%) & 405(60.1 \%) \\ \text { Endline }(n=1226) & 373(60.7 \%) & 286(46.8 \%) \\ \text { Difference } & -6.90 \% & -13.30 \% \\ \text { Arranged blood donors } & & \\ \text { Baseline }(n=1365) & 172(24.9 \%) & 84(12.4 \%) \\ \text { Endline }(n=1192) & 123(20.9 \%) & 98(16.3 \%) \\ \text { Difference } & -4.00 \% & 3.90 \%\end{array}$

Pre-planned for a skilled birth attendant

$\begin{array}{lll}\text { Baseline }(n=1345) & 467(68.2 \%) & 396(55.9 \%) \\ \text { Endline }(n=1226) & 339(55.7 \%) & 238(38.6 \%) \\ \text { Difference } & -12.50 \% & -17.30 \%\end{array}$

Breastfeeding

Initiated breastfeeding within the first hour after birth

$\begin{array}{cll}\text { Baseline }(n=1216) & 471(77.9 \%) & 341(55.8 \%) \\ \text { Endline }(n=1037) & 345(67.4 \%) & 387(73.7 \%) \\ \text { Difference } & -10.50 \% & 17.90 \% \\ \text { Currently breastfeeding } & & \\ \text { Baseline }(n=1385) & 659(93.2 \%) & 640(94.4 \%) \\ \text { Endline }(n=1366) & 603(93.8 \%) & 631(94.5 \%) \\ \text { Difference } & 0.6 \% & 0.1 \%\end{array}$

$6.36 \%(-1.1$ to 13.8$) \quad 0.10 \quad 2.31 \%(-4.8$ to 9.4$)$

0.53

$-7.91 \%(-13.9$ to -1.9$) \quad 0.0098 \quad-9.59 \%(-15.4$ to -3.8$)$

0.0013

Adjusted for clustering by district, maternal age, maternal education and paternal education 
Table 6 Knowledge about birth preparedness in women included in the study compared between intervention and control villages

\begin{tabular}{|c|c|c|c|c|c|c|}
\hline & $\begin{array}{l}\text { Number (\%) of mothers } \\
\text { in intervention villages }\end{array}$ & $\begin{array}{l}\text { Number (\%) of mothers } \\
\text { in control villages }\end{array}$ & $\begin{array}{l}\text { Crude mean } \\
\text { difference }(95 \% \mathrm{Cl})\end{array}$ & $p$ value & $\begin{array}{l}\text { Adjusted mean } \\
\text { difference }^{\text {a }}(95 \% \text { Cl) }\end{array}$ & $p$ value \\
\hline \multicolumn{7}{|c|}{ Knowledge of importance of saving money during pregnancy } \\
\hline Baseline $(n=1398)$ & $605(85.4 \%)$ & $517(74.9 \%)$ & & & & \\
\hline Endline $(n=1291)$ & $509(82.6 \%)$ & $441(65.3 \%)$ & & & & \\
\hline Difference & $-2.8 \%$ & $-9.6 \%$ & $6.77 \%(0.5$ to 13.0$)$ & 0.04 & $4.13 \%(-2.0$ to 10.3$)$ & 0.19 \\
\hline \multicolumn{7}{|c|}{ Knowledge of importance of preplanning travel for birth } \\
\hline Baseline $(n=1392)$ & $623(88.4 \%)$ & $575(83.7 \%)$ & & & & \\
\hline Endline $(n=1289)$ & $540(87.7 \%)$ & $490(72.8 \%)$ & & & & \\
\hline Difference & $-0.7 \%$ & $-10.9 \%$ & $10.18 \%(4.6$ to 15.8$)$ & 0.0004 & $8.46 \%$ (2.9 to 14.0$)$ & 0.003 \\
\hline \multicolumn{7}{|c|}{ Knowledge of importance of arranging a skilled birth attendant } \\
\hline Baseline $(n=1390)$ & $625(88.7 \%)$ & $572(83.5 \%)$ & & & & \\
\hline Endline $(n=1285)$ & $513(83.7 \%)$ & $502(74.7 \%)$ & & & & \\
\hline Difference & $-5.0 \%$ & $-8.8 \%$ & $3.84 \%(-1.9$ to 9.5$)$ & 0.19 & $2.13 \%(-3.5$ to 7.7$)$ & 0.45 \\
\hline
\end{tabular}

${ }^{a}$ Adjusted for clustering by district, maternal age, maternal education and paternal education

Table 7 Predictors of facility delivery or skilled birth attendant among women participating in the endline survey $(n=1376)$

\begin{tabular}{|c|c|c|c|c|}
\hline & \multicolumn{2}{|c|}{ Univariable model $^{a}$} & \multicolumn{2}{|c|}{ Multivariable model $^{a, b}$} \\
\hline & RR $(95 \% \mathrm{Cl})$ & $p$ value & RR $(95 \% \mathrm{Cl})$ & $p$ value \\
\hline \multicolumn{5}{|l|}{ Maternal educational level } \\
\hline No education & Reference & & & \\
\hline Primary school & $1.22(1.09-1.36)$ & 0.0005 & $1.07(0.96-1.19)$ & 0.21 \\
\hline Secondary school or higher & $1.21(1.09-1.33)$ & 0.0003 & $0.99(0.89-1.11)$ & 0.91 \\
\hline Madrassa & $1.10(1.01-1.22)$ & 0.04 & $1.07(0.97-1.18)$ & 0.20 \\
\hline \multicolumn{5}{|l|}{ Paternal educational level } \\
\hline No education & Reference & & & \\
\hline Primary school & $1.15(1.02-1.29)$ & 0.02 & $1.08(0.96-1.22)$ & 0.19 \\
\hline Secondary school or higher & $1.22(1.12-1.33)$ & $<0.0001$ & $1.07(0.98-1.17)$ & 0.12 \\
\hline Madrassa & $1.01(0.91-1.11)$ & 0.89 & $0.96(0.88-1.06)$ & 0.46 \\
\hline \multicolumn{5}{|l|}{ Maternal age (years) } \\
\hline $15-19$ & $1.27(1.12-1.43)$ & 0.0001 & $1.19(1.05-1.34)$ & 0.007 \\
\hline $20-24$ & $1.05(0.96-1.16)$ & 0.29 & $1.01(0.92-1.11)$ & 0.85 \\
\hline $25-29$ & Reference & & & \\
\hline $30-34$ & $1.09(0.98-1.21)$ & 0.10 & $1.08(0.99-1.19)$ & 0.10 \\
\hline $35-40$ & $0.98(0.86-1.11)$ & 0.74 & $1.02(0.9-1.14)$ & 0.80 \\
\hline$>40$ & $0.97(0.82-1.16)$ & 0.75 & $1.02(0.87-1.2)$ & 0.76 \\
\hline Attended at least one antenatal care visit & $1.60(1.43-1.79)$ & $<0.0001$ & $1.41(1.27-1.58)$ & $<0.0001$ \\
\hline \multicolumn{5}{|c|}{ Mothers reported having knowledge about the importance of: } \\
\hline Skilled birth attendance & $1.41(1.26-1.59)$ & $<0.0001$ & $1.12(0.99-1.25)$ & 0.06 \\
\hline Preplanning for travel & $1.47(1.30-1.67)$ & $<0.0001$ & $1.14(1.01-1.3)$ & 0.04 \\
\hline Saving money in preparation for delivery & $1.53(1.37-1.71)$ & $<0.0001$ & $1.32(1.18-1.47)$ & $<0.0001$ \\
\hline
\end{tabular}

${ }^{\mathrm{a}}$ Relative risk estimated by log binomial regression models

${ }^{\mathrm{b}}$ Adjusted for maternal education, paternal education, maternal age, antenatal care attendance, maternal knowledge, clustering by district 
antenatal and postnatal complications improved by $14 \%$ in the intervention compared to the control districts. PNC attendance was maintained in the intervention districts but declined in the control districts. Mothers' knowledge also appeared to improve but there was little change in birth preparedness or newborn care practices.

Overall, our findings are encouraging, as the dose of our programmatic intervention was low. Each woman in our study received only two home visits from the onset of pregnancy to 28 days postpartum. Each CHW performed an average of 45 home visits over the 12-month intervention period (almost four per month); 70\% of women received a first ANC visit, but only $13 \%$ of women received a fourth antenatal visit. Further, $70 \%$ of women received a visit from a CHW on the first 2 days after birth but only $8 \%$ received a PNC visit on day 7 postpartum and only $5 \%$ received a PNC on day 28 postpartum. Over the study period, the levels of conflict and insecurity in both Kandahar and Bamyan provinces increased and restricted movement of some CHWs. Some CHWs were also not allowed by other family members to visit the mothers. A particular barrier was entry to the indoor area of the home, though some CHWs were able to interact with the women in the seating area in front of their home. Competing workload priorities and other employment also restricted the time the CHWs could devote to the home visiting programme. Other challenges included the winter season limiting movement of CHWs and project staff and the dynamic nature of the conflict with new restrictions occurring on a weekly basis.

'Dropout' after initial engagement is a well-known part of 'real world' MCH service delivery [29-31]. Analyses of Demographic and Health Surveys (DHS) conducted in Pakistan, Uganda and Ethiopia describe coverage of 70-80\% at the first ANC visit declining to $10-20 \%$ by the fourth visit $[29,32,33]$. Coverage of CHW home visits $(50-70 \%)$ in 'real world' programmatic settings is also substantially lower than experimental research sites (95-100\%) [8,34,35].

Encouragingly, our study shows that a dose as low as two home visits per pregnant woman can have an important effect on care seeking for service delivery. Increasing the dose of home visits per woman is likely to result in an even greater effect on service use and neonatal morbidity and mortality in our setting in rural Afghanistan. A clear dose response of increasing ANC and PNC service use with increasing intensity of $\mathrm{CHW}$ home visiting has been shown in analyses of observational data from Asia and Africa [8, 36, 37]. Clinical trial data also indicate that neonatal mortality can be reduced by up to $45 \%$ if a coverage of $90-100 \%$ of CHW home visits can be achieved [8,35-38]. Of note, the Ministry is considering implementation of a 'focused' package of home visits limited to one ANC and one PNC visit, which may be more feasible to implement in our study area.
Mechanisms to increase $\mathrm{MCH}$ coverage must include demand generation. A recent Cochrane systematic review reported that $\mathrm{CHW}$ packages that included community mobilisation strategies had a $20 \%$ greater impact on coverage and health outcomes compared to $\mathrm{CHW}$ home visits alone $[8,10]$. In our study, the Ministry of Public Health village level community health action groups were trained in intervention and control districts as part of the health system strengthening strategy. However, their activities were limited throughout the study period due to difficulties in implementing supportive supervision for them.

The intervention was made up of five components (home visits, training curriculum, training programme, supervision, incentives). Supportive supervision and in-kind payments are important for the operationalisation of home visits by volunteer CHWs [8-10, 39, 40]. Many studies have shown that cash and in-kind incentives are highly valued by a volunteer CHW workforce [8-10], yet the training stipend is also an important incentive and must be considered part of the essential intervention package [17]. Support to the CHWs through careful monthly supervision was also essential in this fragile context. However, the difficulties with monthly supervision should not be underestimated and are well described in other studies (e.g. ensuring that the most remote area CHWs are supervised, maintaining transport links and ensuring that the correct travel and accommodation per diem is paid) [8-10]. In Afghanistan, community health supervisors are paid staff members and have been embedded within the health system for the last 10 years $[17,22]$. Their role is much needed and we are working with the Ministry to ensure sustainability of community health supervisor funding, training and supervision.

Overall, our baseline ANC, facility delivery, PNC and other service utilisation rates were similar to Afghanistan DHS 2015 provincial data [2], indicating that our data collection procedures worked well. The 2015 Afghanistan DHS reported slightly lower national level rates than those provided herein (national level ANC (59\%), facility delivery (48\%), PNC to mother (40\%), PNC to infant (9\%)) [2]. However, the Afghanistan DHS also reported a wide variation in coverage including rates as low as $10-20 \%$ in very poor provinces such as Nuristan and Urzugan, where attendance at community health facilities requires a longer than 4-hour walk and where the ability to leave the home is markedly restricted [2]. The modest increases reported in our study will mean much for the mothers and infants who live in similar poor and deprived districts across Afghanistan.

Mothers' knowledge about birth preparedness (saving money for transportation, preplanning travel for facility delivery, preplanning for a SBA) appeared to be maintained in the intervention villages compared to the 
control villages, and also appeared to be significantly predictive of later service use. However, there appeared to be little difference between the intervention and control groups in mothers' actual actions in saving money for transportation, preplanning travel for facility delivery or preplanning for a SBA. These findings may reflect the limited resources and financial decision-making power of the women in the deprived villages that participated in our study. Increasing the intensity and quality of CHW home visiting is needed to change the complex behaviours required for birth preparedness. This includes CHW interaction with other family members, such as fathers and grandfathers, who are the traditional decision-makers in the family setting. Other initiatives, such as cash transfers, demand side financing and provision of local transport options, are also needed $[10,39,40]$.

Little improvement in neonatal care practices was observed. In particular, the proportion of women who initiated breastfeeding within 1 hour of birth declined in the intervention villages by $10 \%$. Other studies have indicated difficulties in changing breastfeeding behaviour at both community and facility level [37, 40]. Our health system strengthening included facility-based ENC training and the importance of early initiation of breastfeeding. However, we had few resources available for ongoing supportive supervision and we were aware that quality of ENC may have been poor in both the intervention and control facilities. We also reported that breastfeeding rates appeared higher after home (260, $76.9 \%)$ than facility deliveries; thus, we feel that more facility-based work is needed in our study area. Increasing rates of referral and care seeking will not be effective in improving morbidity and mortality if health facilities cannot deal with the work load or have poor quality of care [31-33]. Interestingly, our levels of breastfeeding (94\%) were maintained at high levels postpartum in both intervention and control villages at baseline and endline. These data require more investigation as to their accuracy.

Our study had some limitations. It was non-randomised and we purposively chose the intervention and control districts to ensure that both fragile and conflict-affected areas were included. However, we used adjusted difference-in-difference analyses to account for baseline differences and any potentially differing trends in the intervention and control areas [27]. Our intervention dose was low, as described above, due to implementation in difficult conflict-affected areas but we were still able to show an important difference on key outcomes. Our data collectors were allowed to spend only a short period of time in the locations to collect data due to concerns about security. Thus, our evaluation questionnaire, especially the newborn and knowledge sections, was more restricted than previously planned. Our outcome data were also all self-reported and we were not able to verify even a subsample due to project restrictions. Additionally, there was some deterioration in facility delivery, SBA and ANC coverage in the study area, likely due to increasing levels of conflict restricting access; however, longer term surveillance is needed to understand the ongoing trends.

Strengths of our study included our ability to adhere to our data quality and supportive supervision plan, which included random re-visits and verification. Other strengths included our population- and community-based implementation and evaluation. We also had a large sample size and a high response rate. Finally, definitions of 'fragile' and 'conflict affected' also vary; herein, we used clear World Bank and Organisation for Economic Co-operation and Development (OEDC) categories ('fragile' districts requiring external assistance for peacekeeping, governance and financial assistance, and 'conflict affected' districts requiring armed force resulting in battle-related deaths) [19-21], which do not include 'natural disasters' such as earthquakes, floods or fire.

\section{Conclusion}

Overall, our CHW home visiting intervention appeared to improve care seeking and knowledge but not birth preparedness and newborn care practices. Our results indicate that home visiting from CHWs during the antenatal and postnatal periods is likely to be a valuable part of the health system in rural Afghanistan, but that improved training packages are also needed for more complex behaviours such as birth preparedness and newborn care. More work is also needed in strengthening of knowledge and quality of care, especially in specific essential care components including the promotion of early initiation of breastfeeding and other newborn care practices. Further system changes are also required to ensure the sustainability of the $\mathrm{CHW}$ programme in Afghanistan, including performance-based payments for completion of home visits and outcomes such as facility delivery. Increasing the intensity and engagement of CHW with families of pregnant and postpartum women and increasing demand generation is also important. Encouraging new findings have arisen from studies focused on cash transfers to CHWs and mothers for facility delivery and 'mini motorcycle ambulances' for transport of unwell pregnant mothers and their young children in Afghanistan, which will be presented in subsequent papers. Our results also indicate that $\mathrm{CHW}$ home visiting will be highly effective in other conflict-affected countries where women have little power to seek care for themselves or their young children. However, more studies are urgently needed especially from African states and other cultural contexts. 


\section{Appendix}

Table 8 Sociodemographic characteristics of women included in the study in Kandahar and Bamyan villages at baseline

\begin{tabular}{|c|c|c|}
\hline & $\begin{array}{l}\text { Number }(\%) \text { of mothers in } \\
\text { Bamyan intervention and control } \\
\text { villages at baseline }(n=709)\end{array}$ & $\begin{array}{l}\text { Number (\%) of mothers } \\
\text { in Kandahar intervention } \\
\text { and control villages at } \\
\text { baseline }(n=699)\end{array}$ \\
\hline Mother's age (mean, SD) $(n=1397)$ & $27.8(5.9)$ & $28.8(6.7)$ \\
\hline \multicolumn{3}{|c|}{ Mother's education level $(n=1408)$} \\
\hline None & $502(70.8 \%)$ & $365(52.2 \%)$ \\
\hline Primary (grade 6) & $70(9.9 \%)$ & $237(33.9 \%)$ \\
\hline Secondary (grade 9) & $24(3.4 \%)$ & $24(3.4 \%)$ \\
\hline High School (grade 12) & $41(5.8 \%)$ & $6(0.9 \%)$ \\
\hline University & $26(3.7 \%)$ & $5(0.7 \%)$ \\
\hline Madrassa & $46(6.5 \%)$ & $62(8.9 \%)$ \\
\hline \multicolumn{3}{|c|}{ Ethnic language group $(n=1407)$} \\
\hline Dari & 709 (100\%) & $0(0 \%)$ \\
\hline Pashto & $0(0 \%)$ & 699 (100\%) \\
\hline \multicolumn{3}{|c|}{ Husband/Partner's education ( $n=1408)$} \\
\hline None & $272(38.4 \%)$ & $350(50.1 \%)$ \\
\hline Primary (grade 6) & $98(13.8 \%)$ & $212(30.3 \%)$ \\
\hline Secondary (grade 9) & $68(9.6 \%)$ & $51(7.3 \%)$ \\
\hline High school (grade 12) & $64(9.0 \%)$ & $25(3.6 \%)$ \\
\hline University & $70(9.9 \%)$ & $7(1.0 \%)$ \\
\hline Madrassa & $137(19.3 \%)$ & $54(7.7 \%)$ \\
\hline \multicolumn{3}{|c|}{ Husband/Partner's occupation ( $n=1370)$} \\
\hline Does not work & $30(4.4 \%)$ & $33(4.9 \%)$ \\
\hline Servant/household worker & $4(0.6 \%)$ & $19(2.8 \%)$ \\
\hline Farmer & 345 (50.1\%) & $143(21.0 \%)$ \\
\hline Livestock herder & $4(0.6 \%)$ & $28(4.1 \%)$ \\
\hline Labourer & $118(17.1 \%)$ & $142(20.9 \%)$ \\
\hline Street seller/vendor & $2(0.3 \%)$ & $24(3.5 \%)$ \\
\hline Shopkeeper & $55(8.0 \%)$ & $238(35.0 \%)$ \\
\hline Businessman & $11(1.6 \%)$ & 15 (2.2\%) \\
\hline
\end{tabular}

\section{Acknowledgements}

The authors would like to acknowledge the dedicated work of the other members of the study implementation team: Mohammad Attai, Emal Mujadidi, Ahmad Wahidi, Akmal Samsor, Malalai Naziri and Sherin Varkey. The authors would also like to thank colleagues and collaborations from the Ministry of Public Health, UNICEF and other UN agencies.

\section{Funding}

UNICEF Afghanistan Country Office.

\section{Availability of data and materials}

The datasets used and/or analysed during the current study are available from the corresponding author on reasonable request.

\section{Authors' contributions}

KME conceptualised and wrote the first draft of the paper and analyses. The other authors all supervised or conducted the data collection or analyses. All authors reviewed and approved the final manuscript.

\section{Ethics approval and consent to participate}

Ethical approval was obtained from the Afghanistan Ministry of Public Health Institutional Review Board for the implementation and evaluation of this study (study number 361521, received 2 December 2015). Informed written consent was obtained from all mothers prior to the baseline and endline surveys.

\section{Consent for publication}

Ethical approval was obtained from Afghanistan Ministry of Public Health Institutional Review Board for the publication of this study (study number 361521, received 2 December 2015)

\section{Competing interests}

The authors declare that they have no competing interests.

\section{Publisher's Note}

Springer Nature remains neutral with regard to jurisdictional claims in published maps and institutional affiliations. 


\section{Author details}

${ }^{1}$ UNICEF Afghanistan, UNOCA, Jalalabad Road, Kabul, Afghanistan. ${ }^{2}$ Ministry of Public Health, Reproductive, Maternal, Newborn, Child and Adolescent Directorate, Kabul, Afghanistan. ${ }^{3}$ Ministry of Public Health, Community Based Health Care Department, Kabul, Afghanistan. ${ }^{4}$ Save The Children, Kabul, Afghanistan. ${ }^{5}$ Department of Global Health and Population, Harvard TH Chan School of Public Health, Boston, USA.

\section{Received: 13 January 2018 Accepted: 4 June 2018}

Published online: 09 July 2018

\section{References}

1. Akseer N, Bhatti Z, Rizvi A, Salehi AS, Mashal T, Bhutta ZA. Coverage and inequalities in maternal and child health interventions in Afghanistan. BMC Public Health. 2016;16(Suppl 2):797.

2. Central Statistics Organisation. Ministry Public Health (MoPH) and ICF 2017. Demographic and Health Survey. Kabul Afghanistan: Central Statistics Organization; 2015.

3. Akseer N, Kamali M, Husain S, Mirza M, Bakhache N, Bhutta ZA. Strategies to avert preventable mortality among mothers and children in the eastern Mediterranean region: new initiatives, new hope. East Mediterr Health J. 2015;21(5):361-73

4. Akseer N, Salehi AS, Hossain SM, et al. Achieving maternal and child health gains in Afghanistan: a Countdown to 2015 country case study. Lancet Glob Health. 2016:4(6):e395-413.

5. Hirose A, Borchert M, Cox J, Alkozai AS, Filippi V. Determinants of delays in travelling to an emergency obstetric care facility in Herat, Afghanistan: an analysis of cross-sectional survey data and spatial modelling. BMC Pregnancy Childbirth. 2015;15:14.

6. Hirose $A$, Borchert $M$, Niksear $H$, et al. Difficulties leaving home: a crosssectional study of delays in seeking emergency obstetric care in Herat, Afghanistan. Soc Sci Med. 2011;73(7):1003-13.

7. Burki T. Conflict in Afghanistan takes an increasing toll on civilians. Lancet. 2016;388(10040):117-8

8. Lassi ZS, Bhutta ZA. Community-based intervention packages for reducing maternal and neonatal morbidity and mortality and improving neonatal outcomes. Cochrane Database Syst Rev. 2015;3:CD007754.

9. Colvin CJ, de Heer J, Winterton L, et al. A systematic review of qualitative evidence on barriers and facilitators to the implementation of task-shifting in midwifery services. Midwifery. 2013;29(10):1211-21.

10. Glenton C, Colvin CJ, Carlsen B, et al. Barriers and facilitators to the implementation of lay health worker programmes to improve access to maternal and child health: qualitative evidence synthesis. Cochrane Database Syst Rev. 2013:10:CD010414.

11. Yonemoto N, Dowswell T, Nagai S, Mori R. Schedules for home visits in the early postpartum period. Cochrane Database Syst Rev. 2017:8:CD009326.

12. Pfaffmann Zambruni J, Rasanathan K, Hipgrave D, et al. Community health systems: allowing community health workers to emerge from the shadows. Lancet Glob Health. 2017;5(9):e866-e7.

13. The Lancet Global Health. Community health workers: emerging from the shadows? Lancet Glob Health. 2017;5(5):e467.

14. USAID Unicef Institutionalizing Community Health Conference, Johannesberg 2017. http://www.ichc2017.org/sites/default/files/images/Plenary\%205/ Plenary\%205\%20-\%20Jerome\%20Pfaffmann.pdf. Accessed 24 Apr 2018.

15. Black RE, Taylor CE, Arole S, Bang A, Bhutta ZA, Chowdhury AMR, Kirkwood BR, Kureshy N, Lanata CF, Phillips JF, Taylor M, Victora CG, Zhu Z, Perry HB. Comprehensive review of the evidence regarding the effectiveness of community-based primary health care in improving maternal, neonatal and child health: 8. Summary and recommendations of the expert panel. J Glob Health. 2017;7(1):010908.

16. Gopalan SS, Das A, Howard N. Maternal and neonatal service usage and determinants in fragile and conflict-affected situations: a systematic review of Asia and the middle-east. BMC Womens Health. 2017;17(1):20.

17. Newbrander W, Paul I, Feroz F, Stanekzai H. Afghanistan's Basic Package of Health Services: Its Development and Effects on Rebuilding the Health System. 25, 2014. http://moph.gov.af/en/article/afghanistans-basic-packageof-health-services-its-development-and-effects-on-rebuilding-the-healthsystem. Accessed 24 Apr 2018.

18. Frost A, Wilkinson M, Boyle P, Patel P, Sullivan R. An assessment of the barriers to accessing the basic package of health services (BPHS) in Afghanistan: was the BPHS a success? Glob Health. 2016;12(1):71.
19. World Bank. The World Bank Group's harmonized list of fragile situations. 2016. http://pubdocs.worldbank.org/en/586581437416356109/FCS-List-FY16Information-Note.pdf. Accessed 24 Apr 2018.

20. The World Bank Data. Fragile and conflict affected situations. 2018. https:// data.worldbank.org/region/fragile-and-conflict-affected-situations. Accessed 24 Apr 2018.

21. OECD. States of Fragility 2016: Understanding Violence. Paris: OECD Publishing; 2016. https://doi.org/10.1787/9789264267213-en. Accessed 24 Apr 2018

22. Caring for the Newborn at Home. A Training Course for Community Health Workers. http://www.who.int/maternal_child_adolescent/news/events/2012/ CHW_Manual.pdf. Accessed 8 Dec 2017.

23. Centers for Disease Control KPC 2000+ Survey tool. https://www.springnutrition.org/sites/default/files/publications/tools/spring_context_ assessment_tools_all.pdf Accessed 8 Dec 2017.

24. Bierrenbach AL. World Health Organization. Geneva http://www.who.int/tb/ advisory_bodies/impact_measurement_taskforce/meetings/prevalence_ survey/psws_probability_prop_size_bierrenbach.pdf. Accessed 25 Nov 2017.

25. Bierrenbach B. Steps in Applying Probability Proportional to Size and Calculating Basic Probability Weights. Geneva: World Health Organization 2012

26. Bennett S. A Simplified General Method for Cluster Sample Surveys of Health in Developing Countries. http://apps.who.int/iris/bitstream/10665/ 47585/1/WHSQ 1991 44(3) 98-106 eng.pdf. Accessed 8 Dec 2017.

27. Dimick JB, Ryan AM. Methods for evaluating changes in health care policy: the difference-in-differences approach. JAMA. 2014;312(22):2401-2.

28. Spiegelman D, Hertzmark E. Easy SAS calculations for risk or prevalence ratios and differences. Am J Epidemiol. 2005;162(3):199-200.

29. Anastasi $E$, Borchert $M$, Campbell OM, et al. Losing women along the path to safe motherhood: why is there such a gap between women's use of antenatal care and skilled birth attendance? A mixed methods study in northern Uganda. BMC Pregnancy Childbirth. 2015;15:287.

30. Mohan D, LeFevre AE, George A, et al. Analysis of dropout across the continuum of maternal health care in Tanzania: findings from a crosssectional household survey. Health Policy Plan. 2017;32(6):791-9.

31. Singh K, Story WT, Moran AC. Assessing the continuum of care pathway for maternal health in South Asia and sub-Saharan Africa. Matern Child Health J. 2016;20(2):281-9.

32. Iabal S, Maqsood S, Zakar R, Zakar MZ, Fischer F. Continuum of care in maternal, newborn and child health in Pakistan: analysis of trends and determinants from 2006 to 2012. BMC Health Serv Res. 2017;17(1):189.

33. Yaya S, Bishwajit G, Ekholuenetale M, Shah V, Kadio B, Udenigwe O. Timing and adequate attendance of antenatal care visits among women in Ethiopia. PLoS One. 2017;12(9):e0184934.

34. Mbuagbaw L, Medley N, Darzi AJ, Richardson M, Habiba Garga K, OngoloZogo P. Health system and community level interventions for improving antenatal care coverage and health outcomes. Cochrane Database Syst Rev. 2015;12:CD010994

35. Kirkwood BR, Manu A, ten Asbroek AH, et al. Effect of the Newhints homevisits intervention on neonatal mortality rate and care practices in Ghana: a cluster randomised controlled trial. Lancet. 2013;381(9884):2184-92.

36. Friberg IK, Bhutta ZA, Darmstadt GL, et al. Comparing modelled predictions of neonatal mortality impacts using LiST with observed results of community-based intervention trials in South Asia. Int J Epidemiol. 2010; 39(Suppl 1):i11-20.

37. Karim AM, Admassu K, Schellenberg J. Effect of Ethiopia's health extension program on maternal and newborn health care practices in 101 rural districts: a dose-response study. PLoS One. 2013;8(6):e65160.

38. Johnson AD, Thiero O, Whidden C, Poudiougou B, Diakité D, Traoré F, Samaké S, Koné D, Cissé I, Kayentao K. Proactive community case management and child survival in periurban Mali. BMJ Glob Health. 2018 . 3(2):e000634.

39. Wiysonge CS, Paulsen E, Lewin S, Ciapponi A, Herrera CA, Opiyo N, Pantoja T, Rada G, Oxman AD. Financial arrangements for health systems in lowincome countries: an overview of systematic reviews. Cochrane Database Syst Rev. 2017;9:CD011084

40. Mian NU, Alvi MA, Malik MZ, lqbal S, Zakar R, Zakar MZ, Awan SH, Shahid F, Chaudhry MA, Fischer F. Approaches towards improving the quality of maternal and newborn health services in South Asia: challenges and opportunities for healthcare systems. Glob Health. 2018;14(1):17.

41. Islamic Republic of Afghanistan, Central Statistics Organization Afghanistan Living Standards Survey 2013-2014. http://cso.gov.af/Content/files/ALCS/ ALCS\%20ENGLISH\%20REPORT\%202014.pdf. Accessed 22 April 2018. 